\title{
Synergy between the Multiple Supply Chain and Green Supply Chain Management (GSCM) approaches: an initial analysis aimed at fostering supply chain sustainability
}

\author{
Ana Lima de Carvalho ${ }^{1}$, Livia Rodrigues Ignácio ${ }^{1}$, Kleber Francisco Esposto ${ }^{1}$, \\ and Aldo Roberto Ometto ${ }^{1}$
}

\begin{abstract}
The concept of Green Supply Chain Management (GSCM) was created in the 90s to reduce the environmental impacts of productive systems. This approach seeks to improve the environmental performance of all the participants in a supply chain, from the extraction of raw materials to the use and final disposal of the product, through relationships of collaboration or conformity between the parties. The multiple supply chains approach established by Gattorna (2009) brought to light different supply chain configurations based on the segmentation of customers into four psychological types: collaborative, innovative, efficient and dynamic. Given the recency of these approaches, there are still many opportunities to explore their interrelationships and devise ways for incorporating GSCM practices into different supply chains. Based on an analysis of the literature, this paper presents an initial overview of the synergy between GSCM practices and the four multiple supply chain configurations proposed by Gattorna. In the preliminary discussion of this paper, it was concluded that the Continuous Replenishment and Lean supply chains are more likely to incorporate the GSCM approach in their operations, while the Agile and Fully Flexible supply chains are less receptive to GSCM concepts.
\end{abstract}

Keywords: Supply Chain Management, SCM, Multiple Supply Chains, Green Supply Chain Management, GSCM.

\section{Introduction}

Every product has an impact on the environment, be it due to the raw materials it consumes, its production process, or its use and final disposal (Chehebe, 1997). Over the years, companies' attitudes toward environmental management have gradually evolved from a passive to a reactive, and lastly, to a preventive mindset (Hilson, 2003). This evolution stems from the perception that economic value can be generated for the business while simultaneously promoting improved environmental conditions for society. According to Yang, Lin, Chan and Sheu (2010), the fact is that business competitiveness can increase through environmental management practices, which are reflected in cost reductions and high levels of quality and reliability, for example. While traditional production systems exist solely to provide efficiency, accuracy and low costs, the new models are now also geared towards sustainability (Araujo, 2010).

The concept of Green Supply Chain Management (GSCM) emerged from the combination of Supply Chain Management (SCM) and Environmental Management 
(Franco, 2014). Generally speaking, the idea of this approach is based on the premise that environmental actions do not end at the boundaries of an organization (Zhu, Sarkis, \& Geng, 2005; Srivastava, 2007) and cannot be restricted to a single company (Sarkis, 2003). In short, GSCM aims to connect all the links in the supply chain in order to improve the environmental, operational, and economic performance of the individual links and of the chain, and to reduce its negative environmental impacts (Franco, 2014). Despite today's context of global economic crisis, and increasingly competitive markets taken over by large corporate groups, studies have shown that the application of GSCM practices contribute positively to improve the overall business performance because they promote efficiency, cost savings, improved corporate image, competitive advantage and marketing exposure (Rao \& Holt, 2005; Stefanelli, 2014; Zeng, Meng, Yin, Tam, \& Sun, 2010).

In this context, this article presents an initial analysis of the synergy between GSCM practices and the various supply chain configurations. To this end, we adopted the approach of Multiple Chains, whose types are Continuous Replenishment, Lean, Agile and Fully Flexible. The idea was to make a preliminary assessment of the relationship between GSCM and a given supply chain category to determine, for instance, if they are aligned strongly, moderately or not at all, based on the natural characteristics of the chains and the adherence of each category to the GSCM practices.

\section{The evolution of strategies in Supply Chain Management}

"Supply chain management" is not a new term in the literature. Several authors have explored this theme, presenting similar and complementary concepts, with one thing in common: all of them highlight the importance of some strategic guideline for

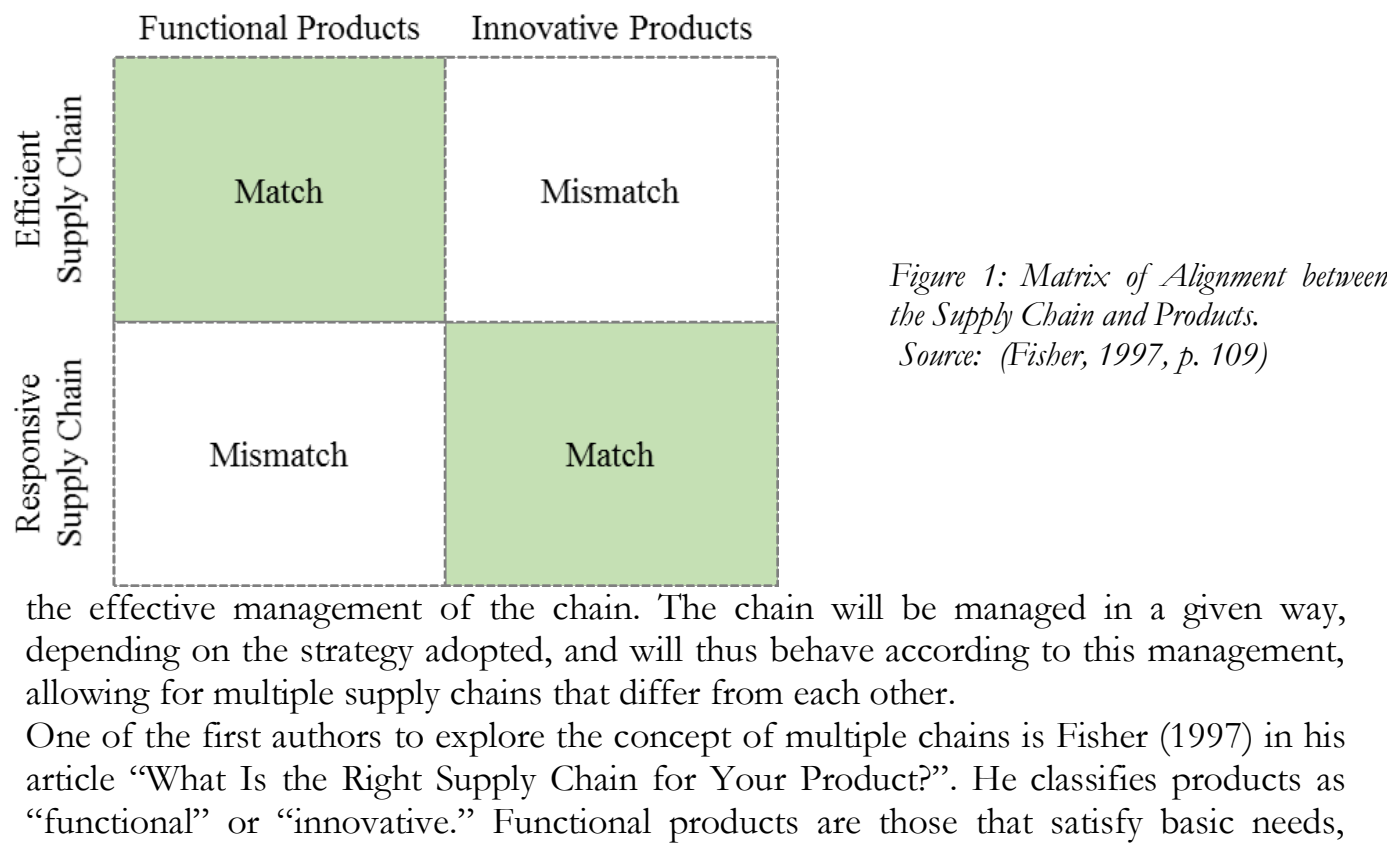


which change little over time and therefore have long life cycles and relatively stable and easily predictable demand. Innovative products, on the other hand, are those with a certain degree of innovation and thus volatile and unpredictable demand and short life cycles. Based on this analysis, he proposes a matrix of supply chain alignment to the type of product sold (Figure 1), where the chain can be efficient (efficiently serves predictable demand at the lowest possible cost) or responsive (responds quickly to unpredictable demand, aiming to minimize stockouts, forced discounts and obsolete inventory).

A few years later, John Gattorna revolutionized the way supply chain management is seen. He introduced Carl Jung's theory of psychological types into the business world (Figure 2), emphasizing the importance of people and culture in a value chain, both internally (staff and leadership) and externally (customers and suppliers).

Gattorna (2009) states that the chain must be dynamically aligned, to enable it to keep track of clients and consumers as their buying behavior evolves over time, i.e., in situations of transformation. Thus, a company should always be aware of its market. He states that the key to design a high-performance value chain is by segmenting the customers (using their buying behavior as criterion) and then adapting the chain to serve these customers, and that there may be multiple chains within the same company. Gattorna then describes the four most common buying behaviors: "Collaborative" (Ia), "Innovative" (Dp), "Efficient" (A) and "Demanding" (Pa). These buying behaviors are served by today's four generic types of value chains: "Continuous Replenishment," "Fully Flexible," "Lean" and "Agile," respectively, which can be described in a matrix of "Customer Relationships" vs. " Predictability of Demand ", as depicted in Figure 3.

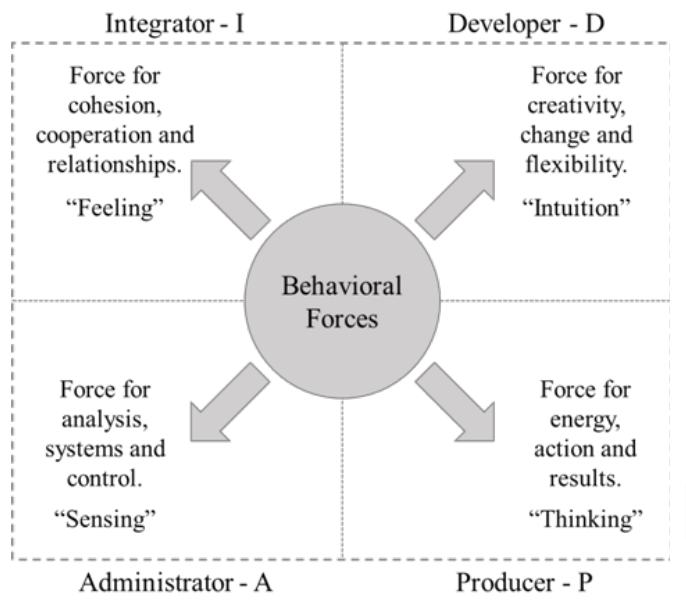

Figure 2: General characteristics of the four dominant behavioral forces or logics. Source: (Gattorna, 2009, $p$. 14)

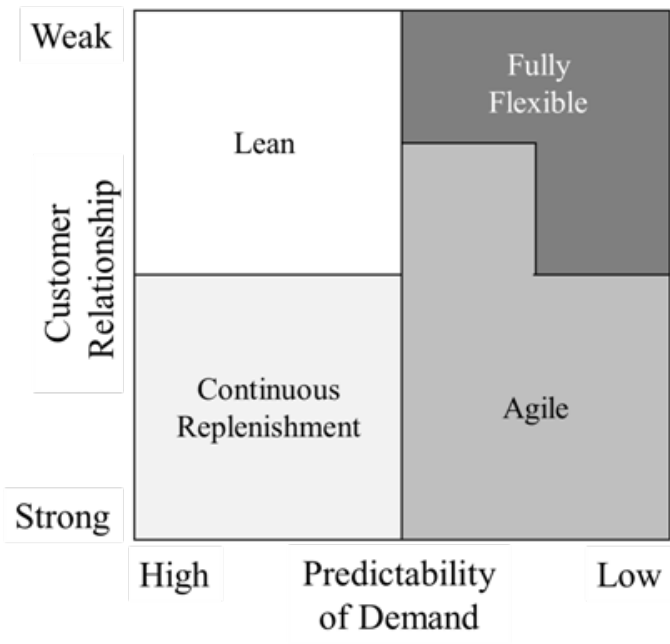

Figure 3: The four generic types of value chains. Source: (Gattorna, 2009, p. 34)

\section{The four main Supply Chain approaches}

\subsection{Continuous Replenishment}

Continuous replenishment value chains are those that focus on maintaining customer relationships (Gattorna, 2009). In the literature, they are often referred to as 
Collaborative Planning, Forecasting and Replenishment (CPFR). A comprehensive definition of CPFR is as follows:

CPFR is a cohesive bundle of business processes whereby supply chain trading partners share information, synchronized forecasts, risks, costs and benefits with the intent of improving overall supply chain performance through joint planning and decision making. Accordingly, CPFR enhances customer demand visibility and matches supply and demand with a synchronized flow of goods from the production and delivery of raw materials to the production and delivery of the final product to the end consumer. The model encompasses different business processes that are subdivided into specific steps or tasks. (Hollmann, Scavarda, \& Thomé, 2015, p. 975-976).

In his work, Gattorna (2009) attributes the following characteristics to a supply chain that adopts a continuous replenishment strategy:

- $\quad$ "Base" type flow, i.e., with a predictable characteristic demand composed of a variety of well known clients.

- Demand is easily manageable through close collaboration with customers, i.e., the customer's behavior is collaborative.

- The focus is on the development of trust-based loyalty relationships.

- The cultural skills are those of group work.

- The predominant style of leadership within the company is that of coaching.

- $\quad$ From the supplier standpoint, the strategy for supplying the company is just-in-time replenishment, where the suppliers are loyal and reliable partners.

\subsection{Lean}

Lean supply chains are based on the management philosophy of Lean Manufacturing derived from the Toyota Production System, TPS (Womack \& Jones, 2004). Their main characteristics are high efficiency, which is the result of strong customer orientation, where waste and activities that do not add value during the course of the process are systematically eliminated, thus reducing unnecessary costs (Lima \& Castro, 2008).

Gattorna's (2009) definition of lean chains differs from that of the aforementioned authors, particularly as it pertains to integration with the client. He states that some clients may require pull production of specific components, but that production is practically pushed into the market to generate the maximum possible efficiency in the process by reducing costs through the formation of economies of scale. Thus, (Gattorna, 2009) envisions the characteristics of the lean chain as:

- "Semi-wave" flow type, i.e., with a relatively regular and fairly predictable pattern of demand.

- $\quad$ Easy to estimate demand, although it may present seasonal variations.

- Its tendency is to present mature and low risk products and/or services.

- The main focus of the lean chain is on economies of scale, synergy gains and lower costs of production and distribution processes.

- It is highly sensitive to price, since its focus is on efficiency in providing consistent lowcost responses to a predictable demand. Thus, the client develops little or no loyalty.

- The internal cultural skill is the hierarchy, with traditional leaders, who follow manuals and well-established procedures. 
- $\quad$ Suppliers are transactional, guided by the process. They promote the reengineering of their processes, making them increasingly simplified, aiming at low costs and high reliability.

\subsection{Agile}

Agile supply chains are less efficient but much more responsive, since they focus strongly on customer needs. This enables them to respond to sudden changes in demand generated by scenarios of uncertainty, owing to the presence of idle capacity in the stages of the process, which appears in three different forms: stocks, labor and production lines (Gattorna, 2009), which can respond immediately to a wide variation in demand, in terms of both volume and product mix.

Gattorna (2009) states that agile chains are characterized by strong customer orientation, especially when responding to demand pull, because they immediately respond to whatever the customer needs. Thus, the author describes the following characteristics for this type of chain:

- "Wave" type flow with highly unpredictable demand, which may be due to promotions, new product launches, unexpected opportunities, and other factors.

- Last minute or non-existent planning, given the unpredictability of demand.

- The chain focuses on responding to the customer's needs in a fast and commercially viable manner, notwithstanding unpredictable demands or differentiated supply conditions.

- The customer's buying profile is demanding, requiring a fast response to his needs, or he will look elsewhere for his demand to be met.

- $\quad$ The cultural skill is rational, with a business tycoon leadership style, i.e., objective, which embraces change, challenges, and is strongly analytical and practical.

- $\quad$ The supplier bases himself on the established scenario, with a planned creativity, i.e., he analyzes strategic sourcing and planning, responding quickly to the customer's need.

\subsection{Fully Flexible}

Lastly, Gattorna (2009) describes fully the flexible chain as an example of an agile chain that companies can make use of in times of extreme customer needs, i.e., which allows the company to continue doing business in times of crisis. Therefore, flexibility (agility) increases the resilience of the supply chain (Tang \& Tomlin, 2008).

Although flexibility is a powerful tool of "defense" to mitigate risks, it can also be used as a "proactive" mechanism of competitiveness (Tang \& Tomlin, 2008). Companies that can adjust internally to respond to fluctuating conditions can have a major advantage over their less flexible competitors (Glatzel, Helmcke, \& Wine, 2009).

Gattorna (2009) underscores the following characteristics for the fully flexible chain:

- $\quad$ "Cavitation type flow, i.e., unplanned demand from unknown customers who sometimes have exceptional emergency requirements.

- No planning, since demand is totally unpredictable.

- Has coverage and distribution strategies aimed at the best possible response.

- Requires innovative solutions (because it responds to emergencies) and is therefore not very price sensitive.

- Cultural skills are business oriented or entrepreneurial, given its innovative nature, requiring visionary leadership. 
- From the supplier point of view, supply is volatile, since it is not known when products/services will be needed. Thus, the type of supplier that typically supplies this chain is opportunistic, taking advantage of a particular emergency situation.

\section{Green Supply Chain Management (GSCM)}

In the past, companies traditionally concentrated their efforts solely on internal measures to improve their environmental performance (Chen, Simon, Reich-Weiser, \& Woo, 2013), such as waste minimization, pollution control, etc. However, this reality has changed, and one of the reasons for this is the awareness that customers do not clearly distinguish between a company and its suppliers (Sarkis, 2006). In the event of a nonconformity, the blame usually falls on the company that owns the product or service rather than on the supplier who supplied defective components or adopted illegal labor practices (Chen et al., 2013).

In this context, several theoretical definitions have been proposed for Green Supply Chain Management (GSCM) since the 1990s (Stefanelli, 2014). However, although the definitions of the main authors and studies (Ageron, Gunasekaran, \& Spalanzani, 2012; Green, Morton, \& New, 1996; Messelbeck \& Whaley, 1999; Min \& Kim, 2012; Rao \& Holt, 2005; Sarkis, 2003; Srivastava, 2007; Vachon \& Klassen, 2006; Zhu et al., 2005; Zhu \& Sarkis, 2004, 2006) do not converge, they share a common denominator which they propose for this approach: the need for the integrated incorporation of the environmental variable in all the links of a supply chain in order to improve its environmental performance and reduce the environmental impacts generated by its network of players (industry, services, suppliers, distributors, consumers, etc.).

The GSCM approach comprises a series of environmental practices and tools (Jabbour \& Jabbour, 2012), which have been grouped in different ways by several authors, including Zhu and Sarkis (2004), Zhu and Sarkis (2006), Zhu, Sarkis and Lai (2008), Vachon and Klassen (2006), Chien and Shih (2007) and Zheng (2010). Based on the analyzed literature, it was found that the most widely accepted division among the publications on this theme is the one proposed by Zhu and Sarkis (2006), which classifies GSCM practices as follows:

- Internal environmental management;

- Green purchasing;

- $\quad$ Cooperation with consumers;

- $\quad$ Ecodesign;

- Recovery of investment.

Internal environmental management consists of activities aimed at the improving the internal environmental, and one of its premises is the support and commitment of top and middle leadership. Examples of this are the pursuit of ISO 14001 certification, the adoption of clean technologies, cross-functional cooperation, etc. (Franco, 2014; Zhu et al., 2008).

Green Purchasing consists of the practice of purchasing from suppliers based on environmental attributes, such as the absence of hazardous substances in the composition of raw materials, reuse of natural resources, etc. (Carter \& Carter, 1998). This category also comprises cooperation with suppliers to meet environmental 
objectives, the environmental labeling of products, audits, the adoption of environmental criteria for selecting suppliers, supplier certification, etc. (Franco, 2014).

Practices of cooperation with consumers generally involve an exchange of knowledge between the parties, such as cooperation with clients for the adoption of environmental packaging, ecodesign and cleaner production (Franco, 2014; Zhu et al., 2008).

Ecodesign corresponds to the actions taken during product design, aimed at minimizing environmental impacts during the product's life cycle, without compromising its cost and its nature. Some ecodesign practices are reduced use of hazardous materials, reduced use of raw materials and energy, etc. (Franco, 2014; Zhu et al., 2008).

The category of Investment Recovery includes ways to reduce the generation of waste and adopt the best form of waste disposal based on cost-benefit, considering, for example, the sale of excess stock/material, the sale of scrap, partnerships with recycling sites, setting up a recycling system or a reverse logistics system (Franco, 2014).

\section{Comparison of Multiple Chains and categories of GSCM practices}

For this analysis, a matrix was developed, following the line presented by Guimarães (2015) in her dissertation on GSCM vs. EIP (eco-industrial parks), containing the five categories of GSCM vis-à-vis the multiple chains of continuous replenishment, lean, agile and fully flexible strategies.

Each GSCM category was analyzed in terms of the main characteristics of the respective type of chain, based on the following question and caption:

Can this category of GSCM practice be aligned with this type of chain?

Symbol and caption:

+ Strong alignment: When the chain allows for the full incorporation of the respective category of GSCM practices, without restrictions, obstacles or inconsistencies;

* Moderate alignment: When the chain allows for the partial incorporation of the respective category of GSCM practices, with some restrictions or obstacles;

- Non-alignment: When the chain does not allows for the incorporation of the respective category of GSCM practices, given its incoherence.

The next section discusses the relationships established in the matrix based on the essence of the GSCM categories and the characteristics of the multiple chains.

\subsection{Continuous Replenishment}

The main focus of the continuous replenishment chain is on customer relationships. Therefore, it is in complete accordance with collaborative practices aimed

\begin{tabular}{|l|c|}
\hline \multicolumn{1}{|c|}{ Category of GSCM Practices } & $\begin{array}{c}\text { Alignment with the } \\
\text { Continuous Replenishment }\end{array}$ \\
\hline Internal Environmental Management & + \\
\hline Green Purchasing & + \\
\hline Cooperation with Consumers & + \\
\hline Ecodesign & + \\
\hline Recovery of Investment & + \\
\hline
\end{tabular}

Figure 4: Analysis of alignment between the categories of GSCM practices and the Continuous Replenishment Chain. 
at sustainable development (Figure 4).

In today's global scenario where efficient environmental practices are increasingly a requirement, customers are looking for suppliers increasingly qualified in this respect, and ISO certification is a requisite in many collaborative chains. Internal environmental management, which is strongly aligned with this chain, is a differentiating factor for many customers who seek suppliers with this level of collaboration.

The characteristic of strong relationships in the continuous replenishment chain includes not only a company's customers but also its suppliers, who are loyal and reliable. Since the entire chain is committed to outstanding environmental performance, practices of selection and cooperation with suppliers that meet certain environmental attributes are imperative. Thus, a focus on green purchasing can be classified as strong alignment.

Cooperation with consumers is a strongly aligned GSCM practice, given the very definition of the continuous replenishment chain, since it is committed to sustainable environmental development.

Ecodesign is also considered a strategy strongly aligned with this chain. Given the highly collaborative nature of this type of chain, the proposal of product development with customer involvement is very common. Therefore, if the chain is oriented toward environmental sustainability, ecodesign would be something totally in tune with this proposal.

Lastly, the category of investment recovery was also considered to be strongly aligned with the continuous replenishment chain. The actions could be taken jointly through a collective effort that would ensure greater effectiveness and efficiency of the processes. Reverse logistics systems, for example, could benefit significantly from collaborative relationships in the chain, since they usually involve all the links in the chain.

\subsection{Lean}

\begin{tabular}{|l|c|}
\hline \multicolumn{1}{|c|}{ Category of GSCM Practices } & $\begin{array}{c}\text { Alignment with the Lean } \\
\text { Chain }\end{array}$ \\
\hline Internal Environmental Management & + \\
\hline Green Purchasing & + \\
\hline Cooperation with Consumers & $*$ \\
\hline Ecodesign & $*$ \\
\hline Recovery of Investment & + \\
\hline
\end{tabular}

Figure 5: Analysis of the alignment between the categories of GSCM practices and the Lean Chain

Given their strong focus on supplying customers reliably and highly efficiently, lean chains involve practices that converge with GSCM practices. However, cost reduction is undoubtedly the main driver for decision making. Thus, as a whole, they can be strongly aligned in a scenario where there is no significant increase in costs. Nevertheless, if the adoption of greener practices entails high costs, their alignment can be considered moderate (Figure 5).

The practices of internal environmental management are strongly present in this approach, since they determine standards and procedures for the conscious and 
controlled use of inputs throughout the chain. This approach is fully aligned with one of the main aspects of the lean philosophy: elimination of waste, characterized by the rational use of raw materials and inputs.

The relentless pursuit of increased levels of efficiency involves aspects that converge with those of GSCM. Strong supplier integration, such as the practice of the milk run involving the use of returnable packaging, significantly reduces pollutant emissions, since raw materials and semi-finished products are collected along a common route that reaches all the suppliers, reducing the number of truck trips, as well as the disposal of cardboard and plastic waste, since returnable containers have a long service life. The alignment can therefore be classified as strong. However, it should be kept in mind that the main driver is cost. Thus, when it comes to selecting suppliers or to incorporating collaborative measures with them, the decision will not always be the one that prioritizes the environmental perspective. In these cases, green purchasing can be seen as moderately aligned. Nevertheless, a strong alignment was adopted for purposes of classification in this work, since this is the tendency of more modern lean chains, due to increasingly stringent legislation and the evolution of society itself, which shows increasing awareness of the issues involved in sustainable environmental development.

As for consumers, their buying profile allows for little or no loyalty to their supplier. Given this scanty collaborativeness, companies that adopt a lean strategy focus on providing maximum possible reliability to customers while keeping their costs low by maximizing the optimization of resources during the process in order to avoid waste and/or unnecessary activities. Their appeal therefore stems from collaboration aimed at offering lower prices in exchange for greater loyalty (push production), which enables internal economies of scale. Greater collaboration is more likely if the client himself is interested in adopting GSCM practices. Therefore, this category was classified as moderately aligned.

Ecodesign was considered to be moderately aligned with the lean chain since, notwithstanding some initiatives in a few specific types of businesses, ecodesign has not become a trend given the high costs usually associated with it. In a scenario where the entire supply chain is committed to ecodesign initiatives, it becomes feasible and aligned with the philosophy of zero waste. Otherwise, it is unlikely to be applied.

From the standpoint of investment or asset recovery, there is a very positive relationship between lean chains and GSCM. The sale of surplus inventory and materials is directly related with lean behavior (zero inventory). Another example is plastic and metal recycling, which is a very common activity aimed at increasing efficiency and reducing costs.

\subsection{Agile}

The overall evaluation of agile chains is that they are moderately aligned with GSCM practices (Figure 6), precisely because their main characteristic is to meet customer needs quickly and efficiently.

The focus on meeting customer demands rapidly and innovatively requires wellstructured internal environmental management, so that the chain's major efforts to adapt to the market do not translate into equally significant impacts on the planet. 
Interestingly, internal environmental management, per se, may be a differentiating factor required by customers, such as the selection of a new ISO 14001-certified supplier.

\begin{tabular}{|l|c|}
\hline \multicolumn{1}{|c|}{ Category of GSCM Practices } & $\begin{array}{c}\text { Alignment with the Agile } \\
\text { Chain }\end{array}$ \\
\hline Internal Environmental Management & + \\
\hline Green Purchasing & $*$ \\
\hline Cooperation with Consumers & $*$ \\
\hline Ecodesign & $*$ \\
\hline Recovery of Investment & $*$ \\
\hline
\end{tabular}

Figure 6: Analysis of the alignment between the categories of GSCM practices and the Agile Chain

Given that the environment in which an agile chain operates is defined by unpredictability, it can be a challenge to establish a range of reliable suppliers. In some cases, a company's urgent momentary needs may lead it to make hasty purchases from suppliers that do not meet all the environmental requisites. At other times, a certified supplier may evaluate his consumer market and decide not to service this or that customer, since better offers are available. Thus, collaborative relationships with suppliers are classified as moderately aligned, since they may occur, albeit with great difficulty.

Relations with customers are based on meeting their specific and unpredictable demands in the shortest possible time. Therefore, it is difficult to establish a collaborative practice aimed at improving the environmental aspects of the demand, since the demand itself is unknown. If the entire chain is aligned in search of a greener performance and the collaborative practices discussed with customers can be put into practice regardless of demand variability, this category becomes feasible. However, in most cases, the collaboration is extremely limited. Thus, this aspect falls within the classification of moderate alignment.

Along similar lines is the concept of ecodesign, which involves efforts to produce "greener" products. However, several factors make ecodesign difficult to implement, such as excess idle capacity in the agile chain, which consumes much more energy than in a situation of flat demand, and the demand itself is unpredictable, which makes the product design much more complex and ends up in production that has had insufficient time to be improved and that generates substantial quantities of waste. Therefore, ecodesign is moderately aligned with GSCM practices.

Investment recovery is moderately aligned with GSCM practices because, although it is not the main focus of agile chains, it can be incorporated, mainly through recycling and scrap disposal activities in partnership with suppliers, aimed at overall cost optimization, thus making it a differentiating factor of the chain. Another factor that classifies investment recovery as moderately aligned is the growing tendency for stringent legislation for the total life cycle of products, such as the obligatoriness of reverse logistics systems, for example. 


\subsection{Fully Flexible Chain}

\begin{tabular}{|l|c|}
\hline \multicolumn{1}{|c|}{ Category of GSCM Practices } & $\begin{array}{c}\text { Alignment with the Fully } \\
\text { Flexible Chain }\end{array}$ \\
\hline Internal Environmental Management & + \\
\hline Green Purchasing & $*$ \\
\hline Cooperation with Consumers & $*$ \\
\hline Ecodesign & - \\
\hline Recovery of Investment & $*$ \\
\hline
\end{tabular}

Figure 7: Analysis of the alignment between the categories of GSCM practices and the Fully Flexible Chain

From all chains, the fully flexible is the one that is less aligned with GSCM practices in general, due to its extremely unpredictable behavior (Figure 7).

Our analysis of the alignment of internal environmental management practices with the fully flexible chain lead us to classify it as strongly aligned. If the chain is structured as fully flexible because of an unexpected business event, it is in fact coherent to present well-structured and consolidated internal environmental management. Thus, like in the agile chain, a rapid change can be prevented from causing potentially disastrous environmental impacts in the chain.

Like in the agile chain, internal environmental management can represent the differentiating factor required by customers, e.g., a possible environmental certification required unexpectedly. It is inferred that, in such situations, the agility required by customers is conceptually based on the fully flexible chain in terms of low sensitivity to costs and virtually unlimited funds, since these are usually supplied by the customers themselves.

The classification of strong alignment is also justified in situations where the fully flexible chain is structured to meet humanitarian disasters. In such cases, robust internal environmental management practices are essential when it comes to responding to natural or man-made disasters. Moreover, internal environmental management practices are usually associated with an entrepreneurial business culture, a proactive leadership style, the ability to deal with unpredictability, and with the collaborative culture, which are also natural characteristics of the fully flexible chain.

For the category of green purchasing vis-à-vis the fully flexible chain, this alignment was classified as moderate. Like the agile chain, given the characteristics of emergency and immediatism of the fully flexible chain, unplanned and hasty purchases can be made from suppliers that are able to meet the demand faster and more effectively. Therefore, the fully flexible chain is very likely to "escape" from what green purchasing establishes, which is aimed at selecting suppliers based on environmental attributes.

However, it makes sense for an organization operating within a fully flexible chain to continuously develop its suppliers to meet all its requirements, including those involving environmental performance, so as to be ready for sudden market changes or to meet emergency needs. At the same time, it is important to emphasize that, from the supplier's standpoint, supply is volatile, since he does not know when certain products or services will be needed. Therefore, the type of supplier that typically services this chain is 
opportunistic, taking advantage of that particular scenario, which classifies this relationship as moderately aligned.

As for the alignment between practices of cooperation with consumers, it was also classified as moderate. This is due to the marked nature of emergency of the fully flexible chain, which would not allow for the development of relevant activities of cooperation with the customer, since the latter may change his buying behavior at any moment. Similar to the agile chain, the relationship with consumers consists of serving them as quickly as possible, which subverts the sense of long-term cooperation projects for this chain. Despite this context, this category of GSCM, when consolidated into a fully flexible chain, can offer its clients not only the mitigation of crises but also further reinforcement in preventing them - serving as a competitive differentiator.

From the point of view of the possible relationship between ecodesign practices and the fully flexible chain, it is clear that they make no sense when taken together. Since the fully flexible chain is unpredictable and its nature is to meet emergencies, be innovative, and handle abrupt changes and critical events that require agility, it would be virtually impossible to link this chain with ecodesign products, since this practice is part of product development, which takes place long before there is a demand for the product. For this chain, it would be a waste of time and effort to design products with high environmental performance in a scenario where the type of product the market may demand is unknown.

The GSCM category of investment recovery was classified as moderately aligned with the fully flexible chain. This is explained by the fact that an organization that engages in practices involving the sale of excess material, recycling, etc., would be neither essential nor highly relevant to the nature of the chain. However, were it to make sense, it would not be incongruous for a fully flexible chain to have some kind of recycling system of the material it produces. Given the unpredictability of demand, the need for innovation and speed, this chain focuses its efforts on serving its customers satisfactorily rather than to be concerned about the recovery of investments.

\section{Conclusions}

This paper sought to present an initial analysis of the relationship between GSCM practices and the multiple supply chain configurations described by Gattorna (2009), namely: continuous replenishment, lean, agile and fully flexible.

The agile and fully flexible supply chains generally presented a moderate alignment with the GSCM concepts, mainly because they require fast response times to demand triggered by adverse needs or even disasters. Thus, they show a greater synergy in terms of compliance with laws and regulations for internal environmental management, especially those related to ISO 14001. The other GSCM categories analyzed here, which are collaboration with customers and suppliers, ecodesign and investment recovery, are strongly influenced by the demand variability and, in some cases, may be entirely nonaligned with these types of supply chain.

The continuous replenishment and lean supply chains show the opposite scenario, mainly owing to the natural characteristics of standardization and collaboration between customers and suppliers in these types of chain, which culminate in strong alignment 
with GSCM practices, particularly in the case of the continuous replenishment chain, which presented no constraints regarding the incorporation of these practices. As for to the lean supply chain, provided the client understands that GSCM practices add value to the process, we consider that these practices can be incorporated into the supply chain. Otherwise, depending on how GSCM practices affect efficiency, the alignment may be only moderate.

In general, it was found that the multiple supply chains show positive tendencies for the incorporation of GSCM concepts. However, the agile and fully flexible supply chains were found to present opportunities for a better understanding of the possibilities of adaptation of their characteristics, especially in supplier relationships, in order to increase their alignment with GSCM practices.

\section{References}

Ageron, B., Gunasekaran, A., \& Spalanzani, A. (2012). Sustainable supply management: An empirical study. International Journal of Production Economics, 140(1), 168-182. http://doi.org/10.1016/j.ijpe.2011.04.007

Araujo, J. B. de. (2010). Desenvolvimento de método de avaliação de desempenho de processos de manufatura considerando parâmetros de sustentabilidade. Universidade de São Paulo.

Carter, C. R., \& Carter, J. R. (1998). Interorganizational Determinants of Environmental Purchasing: Initial Evidence from the Consumer Products Industries. Decision Sciences, 29(3), 659-684. http://doi.org/10.1111/j.1540-5915.1998.tb01358.x

Chehebe, J. R. B. (1997). Análise do ciclo de vida de produtos: ferramenta gerencial da ISO 14000. Rio de Janeiro: Qualitymark.

Chen, Y., Simon, R., Reich-Weiser, C., \& Woo, J. (2013). Green Supply Chain. In D. A. Dornfeld (Ed.), Green Manufacturing: Fundamentals and Applications (pp. 83-102). Springer.

Chien, M. K., \& Shih, L. H. (2007). An empirical study of the implementation of green supply chain management practices in the electrical and electronic industry and their relation to organizational performances. International Journal of Environmental Science and Technology, 4(3), 383-394.

Fisher, M. L. (1997). NoWhat Is the Right Supply Chain for Your Product? Harvard Business Review, 105116.

Franco, D. (2014). Green Supply Chain Management em pequenas e médias empresas do setor químico. Universidade Federal de São Carlos. Retrieved from http://www.bdtd.ufscar.br/htdocs/tedeSimplificado//tde_busca/arquivo.php?codArquivo=8308

Gattorna, J. (2009). Living Supply Chains: Alinhamento Dinâmico de Cadeias de Valor. São Paulo: Pearson Prentice Hall.

Glatzel, C., Helmcke, S., \& Wine, J. (2009). Building a flexible supply chain for uncertain times. McKinsey Quarterly, (4), 193-200. Retrieved from http://www.mckinsey.com/businessfunctions/operations/our-insights/building-a-flexible-supply-chain-for-uncertain-times

Green, K., Morton, B., \& New, S. (1996). PURCHASING AND ENVIRONMENTAL MANAGEMENT: INTERACTIONS, POLICIES AND OPPORTUNITIES. Business Strategy and the Environment, 5(3), 188-197. http://doi.org/10.1002/(SICI)1099-0836(199609)5:3<188::AIDBSE60>3.0.CO;2-P

Guimarães, P. S. (2015). Práticas de green supply chain management em eco-industrial parks: contribuições de uma revisão bibliográfica sistemática e de estudos de caso. Universidade de São Paulo.

Hilson, G. (2003). Defining "cleaner production" and "pollution prevention" in the mining context. Minerals Engineering, 16(4), 305-321. http://doi.org/10.1016/S0892-6875(03)00012-8

Hollmann, R. L., Scavarda, L. F., \& Thomé, A. M. T. (2015). Collaborative planning, forecasting and replenishment: a literature review. International Journal of Productivity and Performance Management, 64(7), 971-993. http://doi.org/10.1108/IJPPM-03-2014-0039 
Jabbour, A. B. L. de S., \& Jabbour, C. J. C. (2012). Evolução da Gestão Ambiental e a Adoção de Práticas de Green Supply Chain Management no Setor Eletroeletrônico Brasileiro. In XXXVI Encontro da ANPAD (p. 15). Rio de Janeiro.

Lima, J. A. M. de, \& Castro, L. F. T. de. (2008). Lean supply chain. um estudo sobre o pensamento enxuto aplicado ao gerenciamento de uma cadeia de suprimentos. In XXVIII Encontro Nacional de Engenharia de Produção (p. 12). Rio de Janeiro.

Messelbeck, J., \& Whaley, M. (1999). Greening the health care supply chain: Triggers of change, models for success. Corporate Environmental Strategy, 6(1), 39-45. http://doi.org/10.1016/S10667938(00)80005-6

Min, H., \& Kim, I. (2012). Green supply chain research: past, present, and future. Logistics Research, 4(1-2), 39-47. http://doi.org/10.1007/s12159-012-0071-3

Rao, P., \& Holt, D. (2005). Do green supply chains lead to competitiveness and economic performance? International Journal of Operations \& Production Management, 25(9), 898-916. http://doi.org/10.1108/01443570510613956

Sarkis, J. (2003). A strategic decision framework for green supply chain management. Journal of Cleaner Production, 11(4), 397-409. http://doi.org/10.1016/S0959-6526(02)00062-8

Sarkis, J. (2006). Greening the Supply Chain. Springer.

Srivastava, S. K. (2007). Green supply-chain management: A state-of-the-art literature review. International Journal of Management Reviews, 9(1), 53-80. http://doi.org/10.1111/j.1468-2370.2007.00202.x

Stefanelli, N. O. (2014). Adoção de práticas de Green Supply Chain Management e desempenho ambiental: um estudo em micro, pequenas e médias empresas da indústria sucroenergética brasileira. Universidade de São Paulo.

Tang, C., \& Tomlin, B. (2008). The power of flexibility for mitigating supply chain risks. International Journal of Production Economics, 116(1), 12-27. http://doi.org/10.1016/j.ijpe.2008.07.008

Vachon, S., \& Klassen, R. D. (2006). Extending green practices across the supply chain. International Journal of Operations \& Production Management, 26(7), 795-821. http://doi.org/10.1108/01443570610672248

Womack, J. P., \& Jones, D. T. (2004). A mentalidade enxuta nas empresas: elimine o desperdício e crie riqueza. Rio de Janeiro: Elsevier.

Yang, C.-L., Lin, S.-P., Chan, Y., \& Sheu, C. (2010). Mediated effect of environmental management on manufacturing competitiveness: An empirical study. International Journal of Production Economics, 123(1), 210-220. http://doi.org/10.1016/j.ijpe.2009.08.017

Zeng, S. X., Meng, X. H., Yin, H. T., Tam, C. M., \& Sun, L. (2010). Impact of cleaner production on business performance. Journal of Cleaner Production, 18(10-11), 975-983. http://doi.org/10.1016/j.jclepro.2010.02.019

Zheng, F. (2010). Practices and Research on Green Supply Chain Management in China and Abroad. In 2010 International Conference on E-Product E-Service and E-Entertainment (pp. 1-4). IEEE. http://doi.org/10.1109/ICEEE.2010.5661341

Zhu, Q., \& Sarkis, J. (2004). Relationships between operational practices and performance among early adopters of green supply chain management practices in Chinese manufacturing enterprises. Journal of Operations Management, 22(3), 265-289. http://doi.org/10.1016/j.jom.2004.01.005

Zhu, Q., \& Sarkis, J. (2006). An inter-sectoral comparison of green supply chain management in China: Drivers and practices. Journal of Cleaner Production, 14(5), 472-486. http://doi.org/10.1016/j.jclepro.2005.01.003

Zhu, Q., Sarkis, J., \& Geng, Y. (2005). Green supply chain management in China: pressures, practices and performance. International Journal of Operations \& Production Management, 25(5), 449-468. http://doi.org/10.1108/01443570510593148

Zhu, Q., Sarkis, J., \& Lai, K. (2008). Confirmation of a measurement model for green supply chain management practices implementation. International Journal of Production Economics, 111(2), 261-273. http://doi.org/10.1016/j.ijpe.2006.11.029 